\title{
Minute Times Microgram per Milliliter per Kilogram per Meter Squared
}

National Cancer Institute

\section{Source}

National Cancer Institute. Minute Times Microgram per Milliliter per Kilogram per Meter

Squared. NCI Thesaurus. Code C111258.

Minutes times micrograms per milliliter, divided by kilograms per meter squared. 